\title{
MODEL UPDATING BASED ON THE DYNAMIC IDENTIFICATION OF A BAROQUE BELL TOWER
}

\author{
MARIELLA DIAFERIO ${ }^{1}$, DORA FOTI ${ }^{1}$, NICOLA IVAN GIANNOCCARO $^{2} \&$ SALVADOR IVORRA $^{3}$ \\ ${ }^{1}$ Polytechnic of Bari, Department of Civil Engineering and Architecture, Bari, Italy. \\ ${ }^{2}$ University of Salento, Department of Innovation Engineering, Lecce, Italy. \\ ${ }^{3}$ University of Alicante, Department of Civil Engineering, Alicante, Spain.
}

\begin{abstract}
The sanctuary of Santa Maria di Loreto (Mola di Bari, Italy) was built in in the sixteen century and it is constituted by a church with a simple hut façade characterized by a fine calcareous rose window and on its left side a high bell tower with heavy bells.

In the present study, a non-destructive dynamic identification of the modal characteristics of the structure has been carried out by firstly organising an experimental setup of environmental measurements with several accelerometers placed on different levels of the bell tower. Secondly, the data acquired by the accelerometers have been elaborated by using modern statistic techniques of operational modal analysis (OMA). Finally,these results have been used for calibrating a complete finite element (FE) model of the bell tower structure that may permit to obtain important information about the state of integrity of the medieval structure. This calibrated model was developed to obtain a preliminary evaluation of the seismic vulnerability of the bell tower by performing a nonlinear static analysis.
\end{abstract}

Keywords: Environmental vibrations, Masonry Tower, Operational Modal Analysis, Seismic Analysis, Structural identification

\section{INTRODUCTION}

The analysis of the seismic vulnerability of historical structures has achieved numerous attentions in order to answer to the public request of preserving the wide building heritage, which in many cases, as for Italy, lays on sites with a high seismic level. However, this analysis requires the definition of a reliable finite element model which is able to estimate the structural response also taking into account the existence of cracks and/or damage. In order to define such model a great amount of the researches have performed dynamic tests on such structures and updated a refined finite element model in order to match the experimental results [1-12].

The present study deals with the dynamic identification and the evaluation of the seismic performances of the historical masonry bell tower of Santa Maria di Loreto in Mola di Bari (Italy). The church was erected in the 1587 at the southern outskirts of the town. The church is located on the seafront. The bell tower (shown in Fig. 1) is aligned with the front wall of the church on its Eastern side and it has a total height of $38.3 \mathrm{~m}$. It has a square plan with a side of about $6.3 \mathrm{~m}$ and it connected to the church for about $9 \mathrm{~m}$. Its brick stone masonry walls have a thickness of about $2 \mathrm{~m}$ at the first body (see Fig. 2), at the second body, where the bells are located, the wall thickness becomes equal to about $1.6 \mathrm{~m}$, while at the third body the thickness is about $0.85 \mathrm{~m}$. The tower shows good preservation conditions at the first body; however, at the second and third bodies (Fig. 2) it presents damages due to the atmospheric exposition, as it stands near the sea. The present paper deals with the seismic vulnerability of the bell tower of the sanctuary. For this purpose, a refined 3D finite element model of the bell tower has been defined, which has been updated and validated by comparing the first natural frequencies with the experimental ones. A nonlinear static analysis has been performed on the aforementioned finite element model of the bell tower in order to evaluate the capacity 

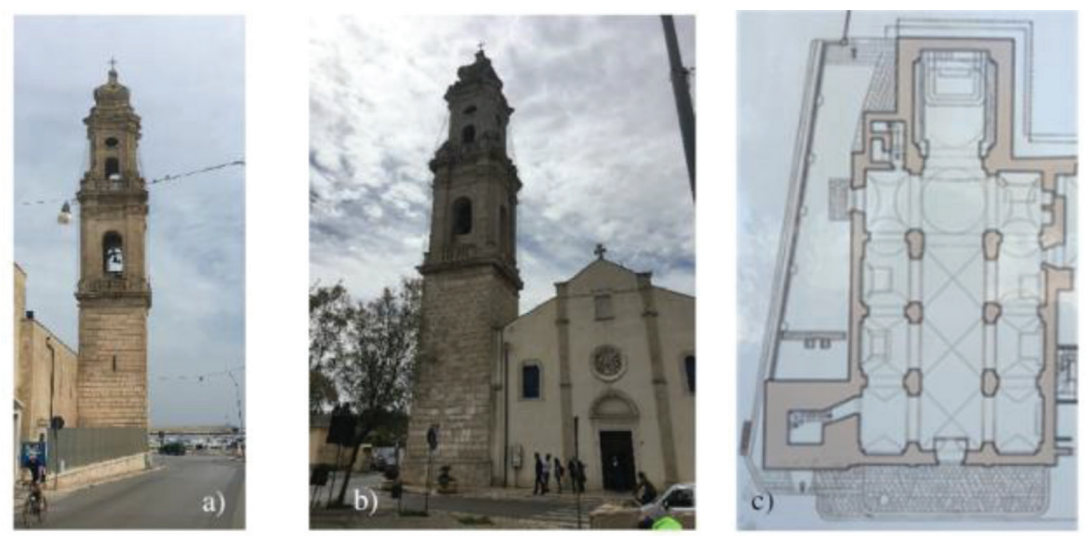

Figure 1: Bell tower of Santa Maria di Loreto (Mola, Bari, Italy). (a) North view. (b) Main façade (c) Plan view of the church with the bell tower.
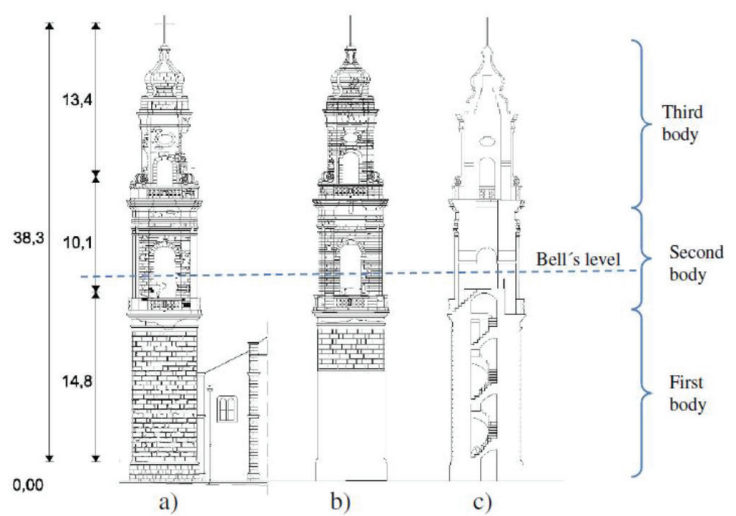

b)

c)

Figure 2: Frontal view of the bell tower of Santa Maria di Loreto (Mola, Bari, Italy). (a) facade in front of sea -North; (b) South facade; (c) Vertical section.

curves along the principal directions. The vulnerability of the bell tower is also evaluated according to the building Italian guidelines using the results of the performed nonlinear static analysis.

This bell tower has the classical structure of three bodies. The first body, resting on an ashlar basement, arrives to the belfry, and it is characterized by four walls practically orthogonal each other, with a thickness of $2 \mathrm{~m}$ without any window or opening. The second body houses the belfry. It is characterized by the opening of four windows with rounded arches, with the base of molded balustrades; pillars projecting creates a very lively language pattern and ends with a sequence of moldings alternating straight and curved profiles.

The third body is characterized by pillars at the corners with swirls of basic pedestal. Each prospect has an opening with rounded arches, this one with a balustrade in front, topped by an oval punch. The bell tower has four bells situated at the height of $18 \mathrm{~m}$. They are situated on a box steel structure not directly anchored to the walls of the bell tower. It is directly supported by the floor of the bell room. Figure 3 shows a general view of the west, north 


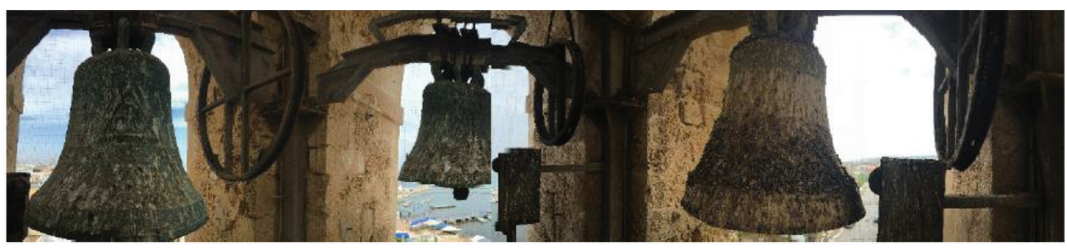

Figure 3: Bells of the tower.

and south bells. The steel structure and the swinging mechanism are very deteriorated by corrosion effects.

\section{THE EXPERIMENTAL CAMPAIGN AND DYNAMICAL IDENTIFICATION}

a) Experimental campaign

A dynamic experimental analysis has been performed on the bell tower of Santa Maria di Loreto church on 21st April 2016. The data have been acquired during a sunny day and with a reduced level of wind and environmental vibrations. Four tests of 15 minutes have been recorded in environmental conditions in order to have a statistical analysis of the identified modal parameters. A reference coordinate system Oxyz has been introduced (see Fig. 4) in such a way that the $x$ axis is parallel to the church façade (see also Fig. 1b).

Moreover, additional tests (two) were carried out by considering the effect of the bells. The first test has been carried out considering the effect of the bells oriented in the $x$ axis direction, the second test considering the bells in y direction.

All the experimental tests have been carried out with $1024 \mathrm{~Hz}$ sampling frequency.

The monitoring system consisted of 10 seismic accelerometers ICP PCB 393B31 with a NI data acquisition system. The DAQ is positioned with the laptop on the base of the tower connected with the accelerometers by flexible shielded cables. The ten uniaxial accelerometers have been connected in couples with opportune blocks in such a way to measure orthogonal components (parallel to $x y$ axis, as shown in Fig. 5) in five different point of the structure. The five points have been selected at three different levels of the bell as shown in Fig. 6 where for each level, the map of the section the accelerometers nomenclature and the reference system are reported. The accelerometers 1, 2, 3, 4 at the higher level (height of $28.6 \mathrm{~m}$ up the bell level), the accelerometer 5, 6, 7, 8 at an average level close to the bell

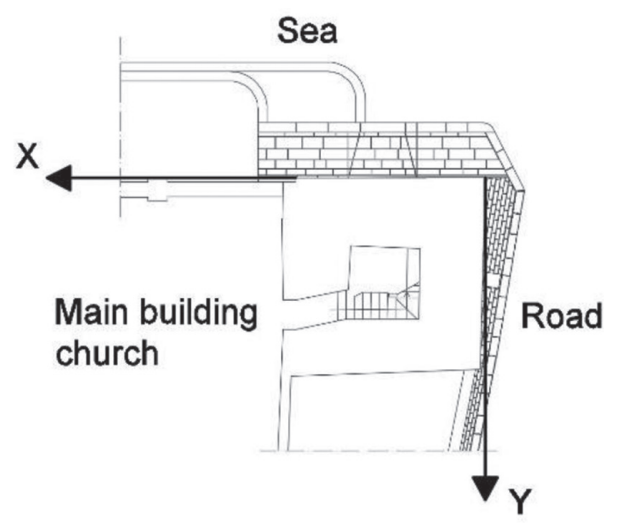

Figure 4: The considered reference system with respect to the geographical bell location. 

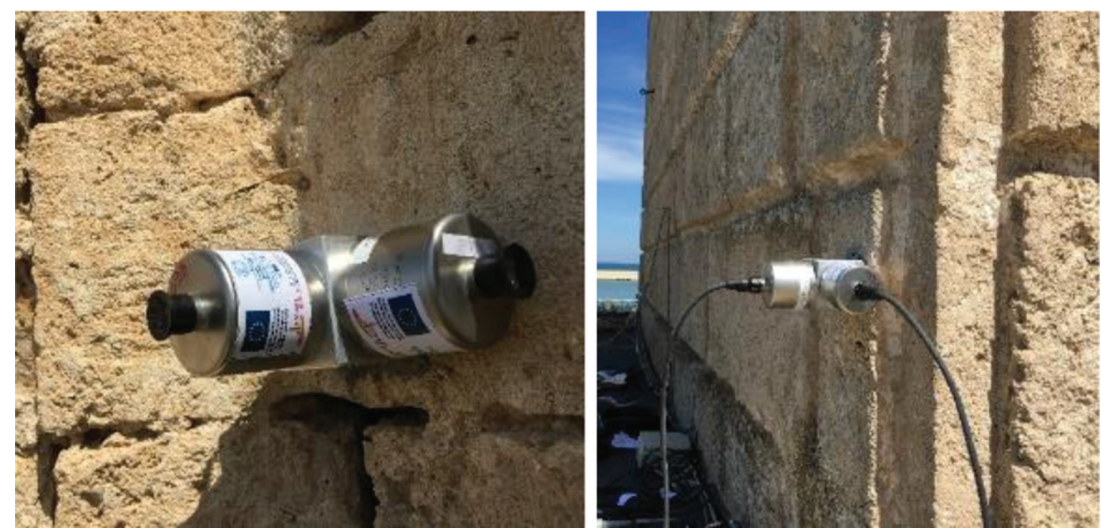

Figure 5: The considered couples of uniaxial accelerometers joined by a block.
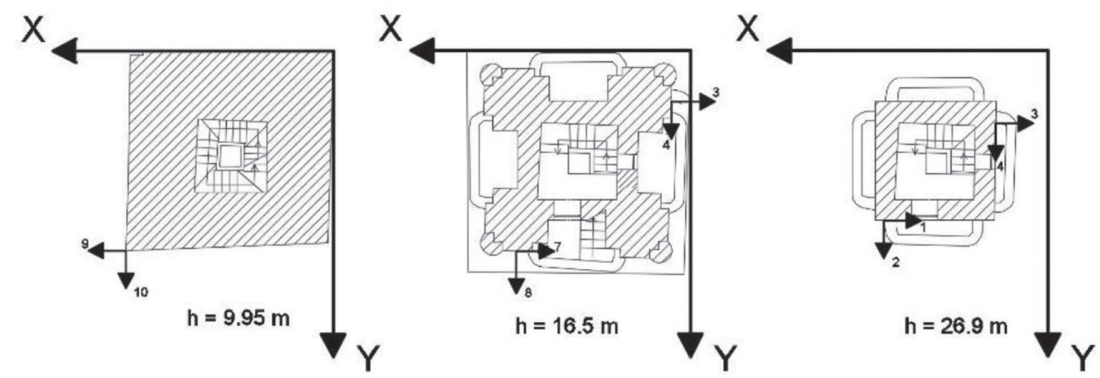

Figure 6: The position of the accelerometers used in the tests.

(height of 16.5 meters) and the accelerometers 9 and 10 are placed in the first body, just upper the connection with the church. Accelerometers 9 and 10 may be considered reference accelerometers. The complete nomenclature, the exact coordinates and the directions (positive and

Table 1: Code and coordinates of the accelerometers used in the test.

\begin{tabular}{llllll}
\hline Accelerometer & Code & Direction & $\mathrm{x}[\mathrm{m}]$ & $\mathrm{y}[\mathrm{m}]$ & $\mathrm{z}[\mathrm{m}]$ \\
\hline 1 & 35063 & $\mathrm{x}-\rightarrow$ & 4.68 & 5.74 & 26.64 \\
2 & 35098 & $\mathrm{y}+\downarrow$ & 4.68 & 5.74 & 26.64 \\
3 & 35211 & $\mathrm{x}-\rightarrow$ & 0.591 & 1.87 & 26.76 \\
4 & 35208 & $\mathrm{y}+\downarrow$ & 0.591 & 1.87 & 26.76 \\
5 & 35089 & $\mathrm{x}-\rightarrow$ & 0.04 & 1.38 & 16.88 \\
6 & 33995 & $\mathrm{y}+\downarrow$ & 0.04 & 1.38 & 16.88 \\
7 & 35205 & $\mathrm{x}-\rightarrow$ & 5.13 & 6.26 & 16.88 \\
8 & 35087 & $\mathrm{y}+\downarrow$ & 5.13 & 6.26 & 16.88 \\
9 & 35206 & $\mathrm{x}+\leftarrow$ & 6.65 & 6.28 & 10.10 \\
10 & 35201 & $\mathrm{y}+\downarrow$ & 6.65 & 6.28 & 10.10 \\
\hline
\end{tabular}


negative with respect to the axis) of the ten accelerometers are reported in a unifying manner in Table 1.

b) Dynamical identification

The four tests developed under environmental conditions have been considered for the dynamical identification of the structure: Test 1, Test 2, Test 3 and Test 4, respectively. A preliminary analysis of the experimental data has been carried out for determining eventual unexpected events on the registered time histories. Figure 7 shows the time histories of accelerometers $1,2,3,4,5,6,7,8$ in Test 1 .

The preliminary check noted unexpected peaks registered for accelerometer 2 in Test 2 , accelerometer 6 in Test 3, accelerometer 3 in Test 4. For this reason, these signals have not been considered in the following dynamical identification.

The dynamical identification has been carried out by using two different and well known techniques, one implemented in the frequency domain (the Curve-fit Frequency Domain Decomposition Modal Analysis, CFDD method) and the second in the time domain (the Stochastic Subspace Identification Modal Analysis, SSI method with UPC (Unweighted Principal Component)).

The analysis has been carried out by searching the first clear experimental frequencies and their corresponding modes for all the tests by using both the methods in such a way to have a statistical overview that guarantees the estimation of the frequencies.

The model realized in an opportune software [13] is shown in Fig. 8, where the arrows indicate the placement and orientation of the accelerometers, the red arrows indicate the accelerometers whose signal is used for the frequencies identification. In Fig. 9 the results of the CFDD identification (for Test 3) and in Fig. 10 the results of SSI identification (Test 1).

The identification results of the four experimental tests in environmental condition are summarized in Table 2, where an analysis about the statistical repeatability is also reported. It is evident the excellent repeatability of the first three identified frequencies for almost all the tests with both the considered techniques. The average value of $1.69 \mathrm{~Hz}$ may be considered for the first frequency, 1.75 for the second one and 5.33 for the third one, with a very low standard deviation between the different tests.
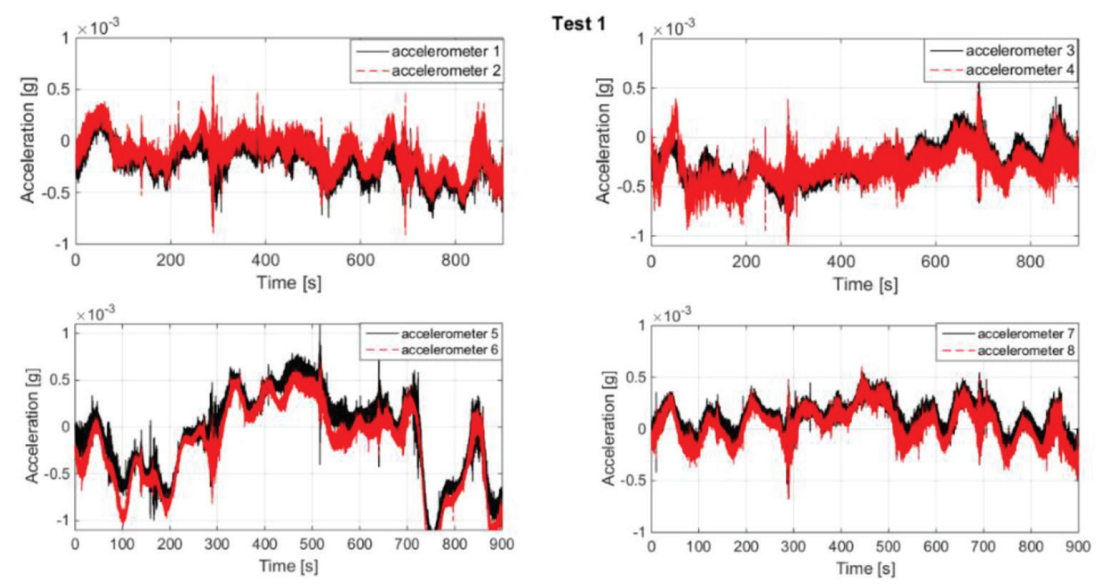

Figure 7: Time histories for Test 1. 

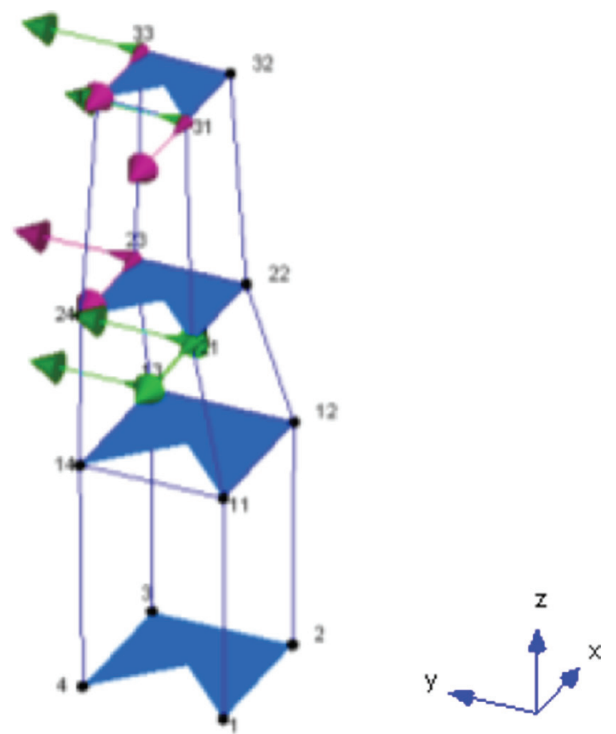

Figure 8: Model used for analysing the experimental data.

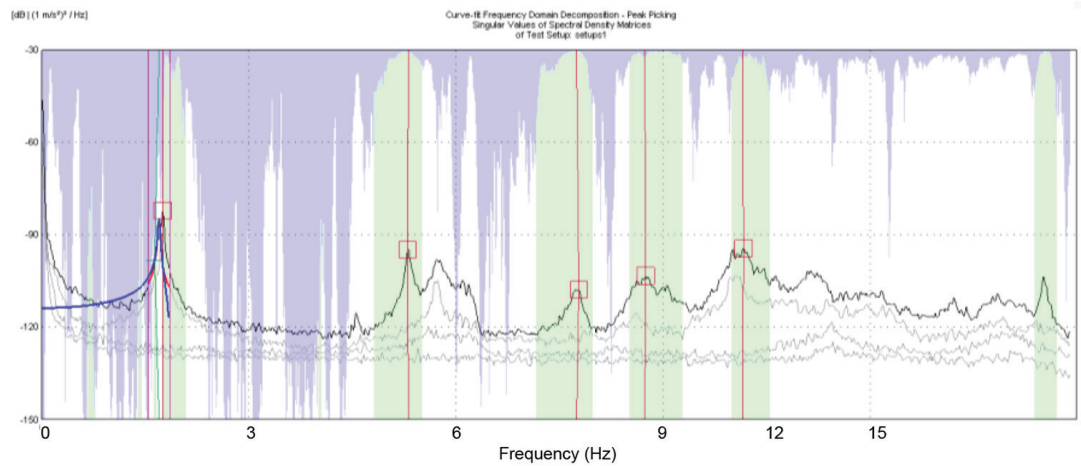

Figure 9: CFDD identification results (Test 3). Automatically detected modes: Mode 1: 1.696 $\mathrm{Hz}$, Mode 2: $1.752 \mathrm{~Hz}$, Mode 3: $5.309 \mathrm{~Hz}$, Mode4: $7.748 \mathrm{~Hz}$, Mode $5(8.738 \mathrm{~Hz}$, Mode 6: $10.16 \mathrm{~Hz}$ ).

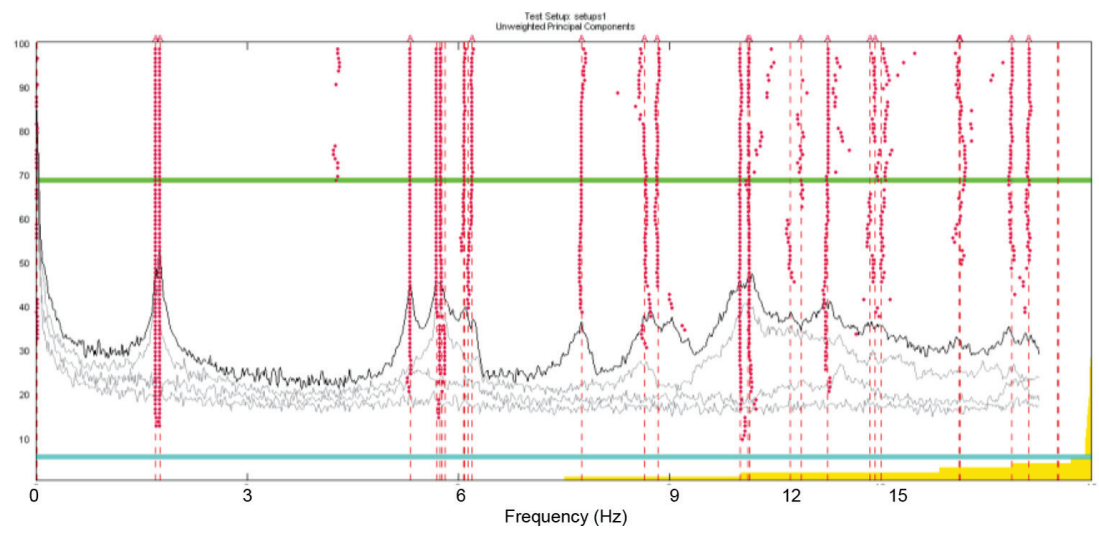

Figure 10: SSI identification results (Test1). 
Table 2: Identified frequencies $[\mathrm{Hz}]$ for the environmental tests and statistical repeatability.

\begin{tabular}{lllllllllll}
\hline & Test1 & Test1 & Test2 & Test2 & Test3 & Test3 & Test4 & Test4 & Aver. & Stand. \\
Freq & CFDD & SSI & CFDD & SSI & CFDD & SSI & CFDD & SSI & value & Dev. \\
\hline 1 & 1.67 & 1.70 & 1.70 & 1.71 & - & 1.70 & 1.69 & 1.69 & 1.694 & $1.210^{-3}$ \\
2 & 1.75 & 1.75 & 1.75 & 1.75 & 1.76 & 1.76 & - & 1.76 & 1.754 & $5.310^{-4}$ \\
3 & - & 5.38 & 5.31 & - & 5.30 & 5.34 & 5.32 & 5.33 & 5.330 & $2.810^{-3}$ \\
\hline
\end{tabular}

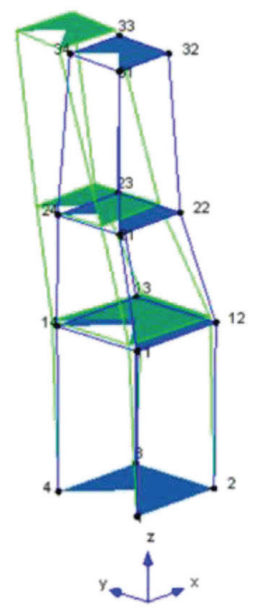

(a)

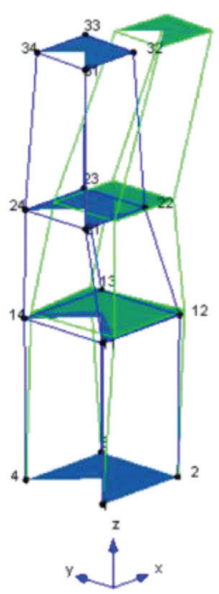

(b)

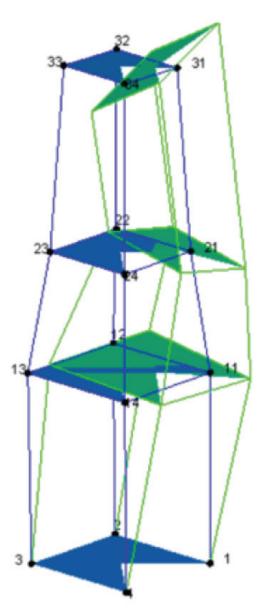

(c)

Figure 11: Experimental mode shapes. (a) First mode, (b) second mode and (c) third mode.

Other higher frequencies are also evident in the CFDD and SSI diagram shown in Figs 9 and 10; but for the validation of a sufficiently accurate FE model of the bell tower, the first three frequencies have been considered enough for guaranteeing a good matching. Moreover, the higher frequencies do not have a so clear repeatability in all the tests.

The mode shapes associated to the identified frequencies are depicted in Fig. 11 and may be clearly considered purely flexional (first flexional) for the first two frequencies (along y axis the first mode, along $\mathrm{x}$ axis the second mode) and torsional for the third identified frequency.

\section{THE NUMERICAL MODEL}

The aim of the performed structural identification was the evaluation of the Young modulus $\mathrm{E}$ and density w of the masonry, and of the degree of constraint due to the adjacent church to the bell tower.

This evaluation is performed, as a first approximation, modelling the tower walls by means of shell elements having the same geometrical characteristics of the tower and a constant Young's modulus. Moreover, the tower has been assumed fixed at the base and a preliminary analysis has been performed assuming $\mathrm{E}=1080 \mathrm{MPa}$ and $\mathrm{w}=1630 \mathrm{~kg} / \mathrm{m}^{3}$ [14]. The model 


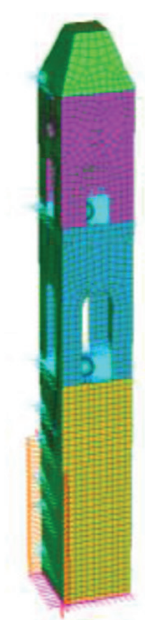

Figure 12: Finite element model of the bell tower of Santa Maria di Loreto (Mola, Bari, Italy).

is defined by means of 3498 shell elements of the type QUAD4 which are defined by means of 4 nodes each one with six degrees of freedom [15]. The model (Fig. 12) has 3654 nodes and three structural masses located at the centre of each floor; moreover, the stairs and the bells have been considered as non-structural masses (Fig. 12).

Two different hypotheses have been adopted: (i) the church is not able to constrain the tower, which behaves as an isolated tower; (ii) the tower is fully constrained by the church [14]. The comparison between the natural frequencies of the abovementioned model and the experimental ones allows concluding that the adjacent church affects the level of constraint of the tower and cannot be neglected in the structural analysis. Thus, here a new model has been adopted which is been obtained from the one discussed in Ref. [14] by updating the Young modulus, the density and the constraints due to the church. In detail, the church is modelled by means of elastic springs acting along the directions of the church walls.

After performing a sensitivity analysis, which for sake of conciseness is not here discussed, it has been adopted a Young's modulus equal to $1500 \mathrm{MPa}$ and a density of $1500 \mathrm{~kg} / \mathrm{m}^{3}$, while the stiffness of the elastic springs is varied in order to match the experimental

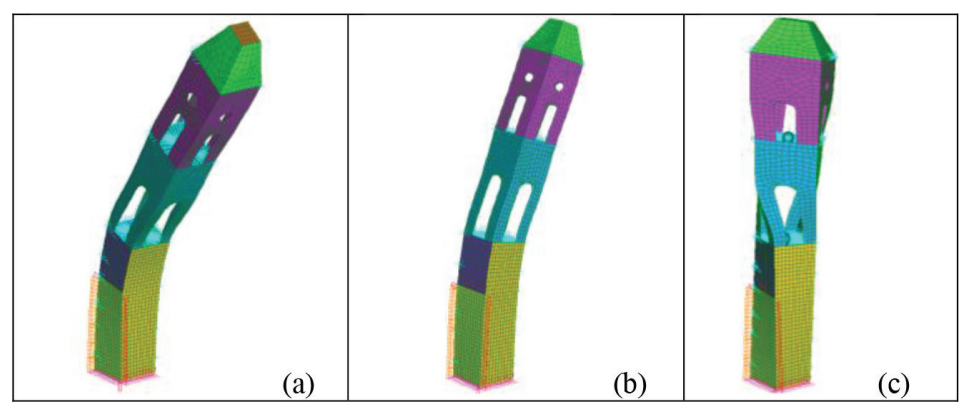

Figure 13: Numerical first three natural modes of the bell tower of Santa Maria di Loreto (Mola, Bari, Italy): (a) first flexural mode along the direction normal to the main façade of the church: $\mathrm{f}_{1}=1.698 \mathrm{~Hz}$; (b) second flexural mode along the direction of the main façade of the church: $f_{2}=1.751 \mathrm{~Hz}$; and (c) third torsional mode: $f_{3}=5.310 \mathrm{~Hz}$. 
Table 3: Comparison between experimental and numerical frequencies.

\begin{tabular}{lllll}
\hline $\begin{array}{l}\text { MODE } \\
\text { frequency [Hz] }\end{array}$ & $\begin{array}{l}\text { Experimental } \\
\text { frequency }[\mathrm{Hz}]\end{array}$ & Difference [\%] & $\begin{array}{l}\text { MAC Experimental/ } \\
\text { Numerical }\end{array}$ \\
\hline 1 & 1.694 & 1.698 & 0.2 & $80.7 \%$ \\
2 & 1.754 & 1.751 & 0.2 & $79.5 \%$ \\
3 & 5.330 & 5.310 & 0.4 & $18.1 \%$ \\
\hline
\end{tabular}

frequency. The model has elastic springs along the connection with the main façade of the church and acting along this direction whose stiffness is equal to $10^{6} \mathrm{KN} / \mathrm{m}$, and elastic springs acting along the direction orthogonal to the previous one and located along the connection with the church whose stiffness is equal to $10^{6} \mathrm{KN} / \mathrm{m}$. In Fig. 13 , the first three natural modes of the bell tower model are shown.

As it can be easily verified in Table 3, there is a good agreement between experimental (average value) and numerical frequencies. The comparison allows considering the structural model reliable to prevent the dynamic response of the structure. In Table 3, the Modal Assurance Criterion (MAC) between the experimental and the numerical modes is also reported. The MAC values are satisfying for the first two flexural modes and this result allows considering the model reliable for the following nonlinear static analysis.

\section{THE NONLINEAR STATIC ANALYSIS}

The area of Mola di Bari (Italy) is a seismic prone zone. According to the actual Italian building code [16] the site is characterized by the response horizontal spectrum, with behaviour factor $\mathrm{q}=2.25$, reported in Fig. 14 in terms of Peak Ground Acceleration (PGA) at the bedrock $\mathrm{a}_{\mathrm{g}}$ versus the return period $T_{R}$. The PGA at the bedrock with a 475 years return period is $a_{g}=0.091 \mathrm{~g}$.

In order to evaluate the seismic vulnerability of the examined tower, a pushover analysis has been performed on the validated finite element model. In accordance with the Italian building code [16], the tower has been subjected to horizontal forces acting along the principal axes and concentrated at the lumped structural masses. The forces are established in accordance with the eqn (1):

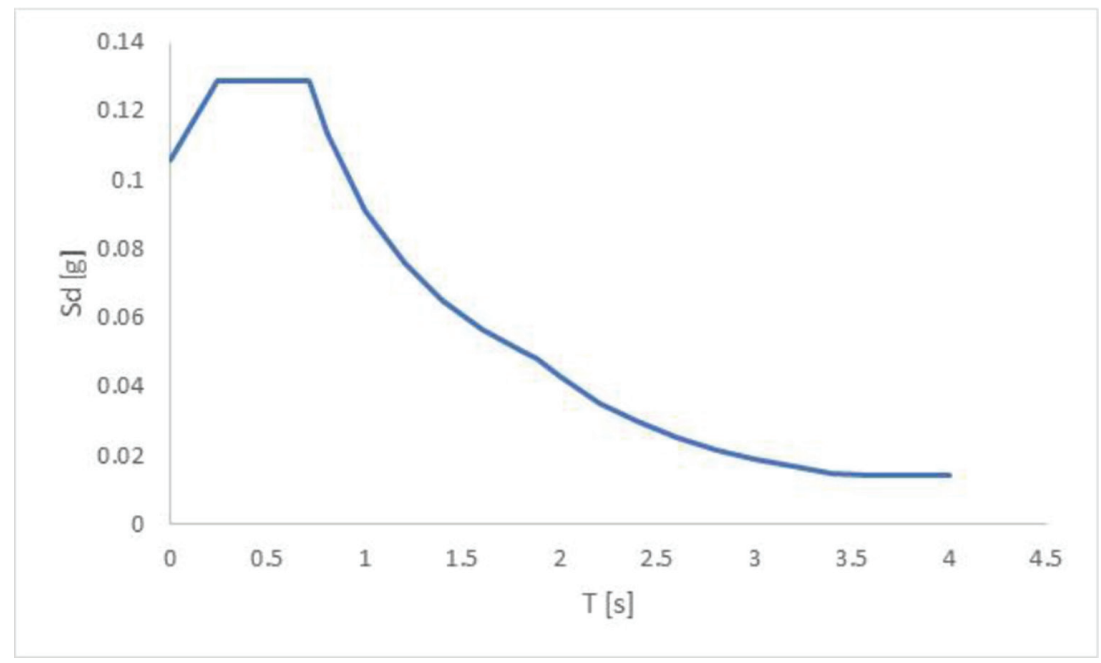

Figure 14: Design horizontal spectrum for Mola di Bari (Italy) [16]. 


$$
F_{i}=F_{h} \frac{z_{i} W_{i}}{\sum_{j=1}^{n} W_{j} z_{j}} \text { with } F_{h}=S_{d}\left(T_{1}\right) \frac{W \lambda}{g}
$$

where $F_{i}$ is the i-th concentrated force located at the i-th lumped mass; $W_{\dot{j}}$ is the weight of the $\mathrm{i}$-th mass, $z_{i}$ is the altitude of the i-th mass respetct to the foundation, $S_{d}\left(T_{1}\right)$ is the design horizontal spectral value for the first natural period of the structure, $W$ is the total weight of the structure, $\lambda=1$ and $g$ the gravity acceleration. Figure 15 shows the direction and position of forces presented in eqn (1) on the structural model of this bell tower.

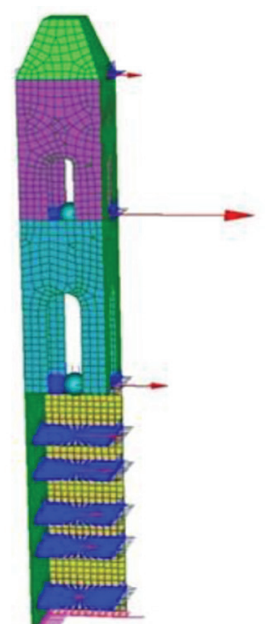

Figure 15: View of the horizontal forces for the pushover analysis of the bell tower of Santa Maria di Loreto (Mola di Bari, Italy).

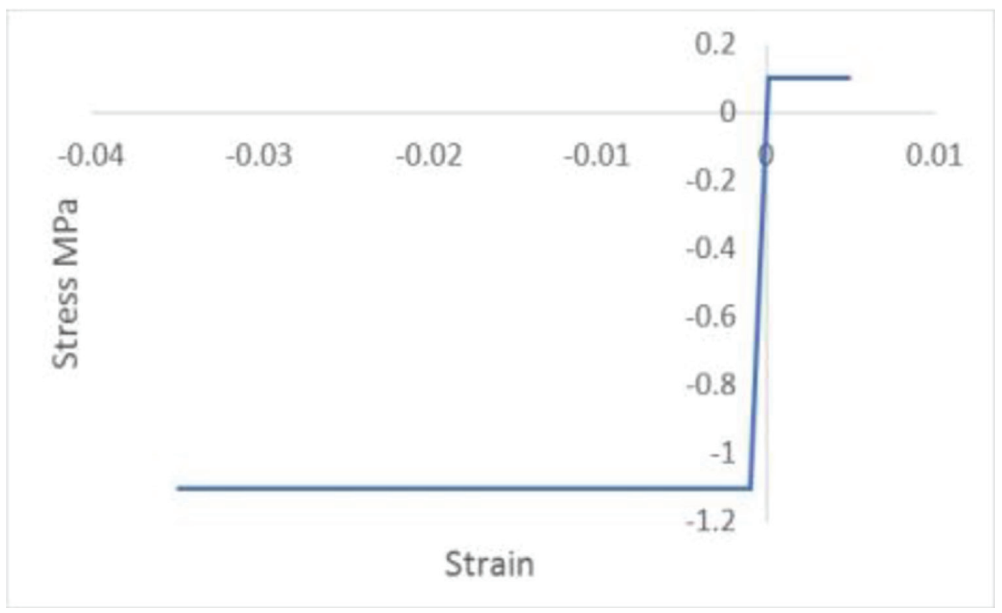

Figure 16: Adopted constitutive law for masonry. 


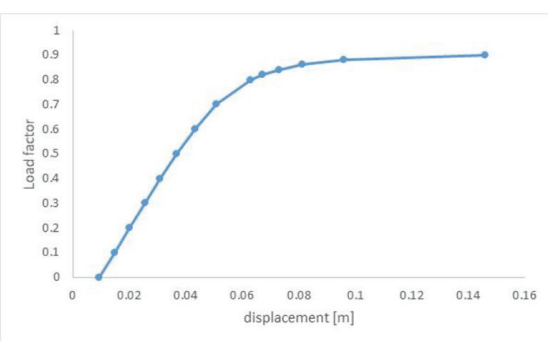

(a)

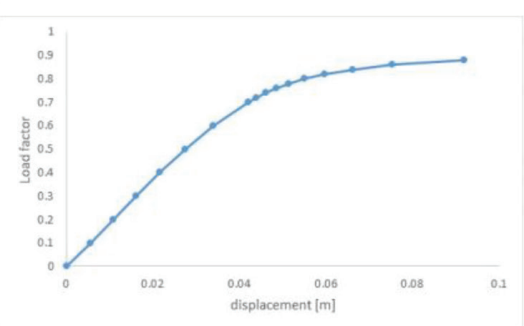

(b)

Figure 17: Capacity curves of the bell tower of Santa Maria di Loreto (Mola di Bari, Italy):

(a) forces acting along the $\mathrm{x}$ axis and (b) forces acting along the $\mathrm{y}$ axis.

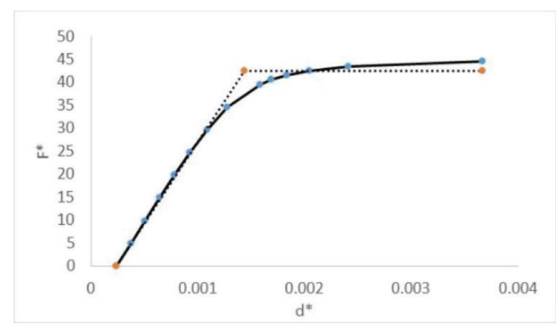

(a)

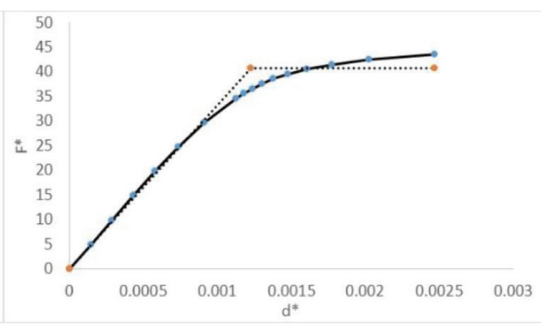

(b)

Figure 18: Equivalent capacity curves and bilinear curves of the bell tower of Santa Maria di Loreto (Mola di Bari, Italy): (a) forces acting along the $\mathrm{x}$ axis and (b) forces acting along the y axis.

The nonlinear static analysis has been performed adopting for the masonry the constitutive law in Fig. 16 where the negative values are related to compression forces (stress) while the positive values represent tensions.

In Fig. 17 the capacity curves evaluated along the $\mathrm{x}$ direction and the $\mathrm{y}$ direction are plotted.

In order to evaluate the seismic vulnerability, the equivalent Single Degree of Freedom (SDF) system has been obtained. In detail, the capacity curve has been modified by introducing the modifications indicated in eqn (2):

$$
F^{*}=\frac{F}{\Gamma} d^{*}=\frac{d}{\Gamma}, \text { where } \Gamma=\frac{\sum m_{i} \Phi_{i}}{\sum m_{i} \Phi_{i}^{2}}
$$

Figure 18 shows the equivalent bilinear capacity curves of the SDF equivalent system for each one of the principal directions.

The bilinear capacity curves evidence maximum displacement values equal to $0.031 \mathrm{~m}$ along the $\mathrm{x}$ axis and equal to $0.021 \mathrm{~m}$ along the $\mathrm{y}$ axis, while the maximum displacement demand, according with Ref. [16], is equal to $0.42 \mathrm{~m}$ and $0.37 \mathrm{~m}$ along the $\mathrm{x}$ and $\mathrm{y}$ axis, respectively.

\section{CONCLUSION}

This paper presents a preliminary analysis of the structural behaviour of Santa Maria di Loreto bell tower. The structural numerical model was calibrated with the dynamic experimental results with a good level of approximation for the complex behaviour of masonry 
structures. The non-linear analysis developed by the application of a pushover analysis on the calibrated numerical model applying the Italian Standards concludes the high seismic vulnerability of this structure and the probably collapse under the proposed seismic loads for Mola di Bari area.

\section{REFERENCES}

[1] Lourenço, P.B., Computations of historical masonry constructions. Pro Structural Engineering, 4(3), pp. 301-319, 2002. https://doi.org/10.1002/pse.120

[2] Gentile, C. \& Saisi, A., Ambient vibration testing of historic masonry towers for structural identification and damage assessment. Construction and Building Material, 21(6), pp. 1311-1321, 2007. https://doi.org/10.1016/j.conbuildmat.2006.01.007

[3] Russo, G., Bergamo, O., Damiani, L. \& Lugato, D., Experimental analysis of the "Saint Andrea" Masonry Bell Tower in Venice. A new method for the determination of “Tower Global Young's Modulus E. Engineering Structures, 32, pp. 353-360, 2010. https://doi.org/10.1016/j.engstruct.2009.08.002

[4] D’Ambrisi, A., Mariani, V. \& Mezzi, M., Seismic assessment of a historical masonry tower with nonlinear static and dynamic analyses tuned on ambient vibration tests. Engineering Structures, 36, pp. 210-219, 2012. https://doi.org/10.1016/j.engstruct.2011.12.009

[5] Foti, D., Diaferio, M., Giannoccaro, N.I. \& Ivorra, S., Structural identification and numerical models for slender historical structures. Handbook of Research on Seismic Assessment and Rehabilitation of Historic Structures, pp. 674-703, 2015. https://doi.org/10.4018/978-1-4666-8286-3.ch023

[6] Ivorra, S., Brotóns, V., Foti, D. \& Diaferio, M., A preliminary approach of dynamic identification of slender buildings by neuronal networks. International Journal of NonLinear Mechanics, 80, pp. 183-189, 2016. https://doi.org/10.1016/j.ijnonlinmec.2015.11.009

[7] Ramos, L., Marques, L., Lourenco, P., De Roeck, G., Campos-Costa, A. \& Roque, J., Monitoring historical masonry structures with operational modal analysis: two case studies. Mechanical Systems and Signal Processing, 24(5), pp. 1291-1305, 2010. https://doi.org/10.1016/j.ymssp.2010.01.011

[8] Diaferio, M., Foti, D., Gentile, C., Giannoccaro, N.I. \& Saisi, A., Dynamic testing of a historical slender building using accelerometers and radar. Prooceedings of 6th International Operational Modal Analysis Conference, IOMAC 2015; Abba HotelGijon; Spain; 12-14 May 2015.

[9] Betti, M., Orlando, M. \& Vignoli. A., Static behaviour of an Italian medieval castle: damage assessment by numerical modelling. Computers and Structures, 89(21-22), pp. 1956-1970, 2011. https://doi.org/10.1016/j.compstruc.2011.05.022

[10] Diaferio, M., Foti, D. \& Giannoccaro, N.I., Identification of the modal properties of a squat historic tower for the tuning of a FE model. Proocedings 6th International Operational Modal Analysis Conference, IOMAC 2015; Abba Hotel Gijon; Spain; 12-14 May 2015. 
[11] Gentile, C. \& Saisi, A., Operational modal testing of historic structures at different levels of excitation. Construction and Building Materials, 48, pp. 1273-1285, 2013. https://doi.org/10.1016/j.conbuildmat.2013.01.013

[12] Tomaszewska, A. \& Szymczak, C., Identification of the Vistula Mounting tower model using measured modal data. Engineering Structures, 42, pp. 342-348, 2012. https://doi.org/10.1016/j.engstruct.2012.04.031

[13] Artemis Modal Pro v4.5. Structural Vibrations Solutions. Aalborg, Denmark. 2016.

[14] Ivorra, S., Foti, D., Diaferio, M. \& Carabellese, I., Preliminary OMA results on a soft calcarenite stone bell-tower in Mola di Bari (Italy). Prooceedings of 7th International Operational Modal Analysis Conference, IOMAC 2017; Ingolstadt - Germany; 10-12 May 2017.

[15] Strauss 7 Finite element analysis system. Strand7 Pty Ltd, available at: www.strauss7.com

[16] NTC. Norme tecniche per le costruzioni. D.M. Ministero Infrastrutture e Trasporti 14 gennaio 2008, G.U.R.I. February 4th 2008, Roma, Italy. 